\title{
Global Metal Use Targets in Line with Climate Goals
}

\author{
Takuma Watari,* Keisuke Nansai, Damien Giurco, Kenichi Nakajima, Benjamin McLellan, \\ and Christoph Helbig
}

Cite This: Environ. Sci. Technol. 2020, 54, 12476-12483

Read Online

\section{ACCESS \\ 山lll Metrics \& More \\ Article Recommendations \\ Supporting Information}

ABSTRACT: Metals underpin essential functions in modern society, yet their production currently intensifies climate change. This paper develops global targets for metal flows, stocks, and use intensity in the global economy out to 2100 . These targets are consistent with emissions pathways to achieve a $2{ }^{\circ} \mathrm{C}$ climate goal and cover six major metals (iron, aluminum, copper, zinc, lead, and nickel). Results indicate that despite advances in low-carbon metal production, a transformative system change to meet the society's needs with less metal is required to remain within a $2{ }^{\circ} \mathrm{C}$ pathway. Globally, demand for goods and services over the 21 st century needs to be met with approximately $7 \mathrm{t} /$ capita of metal stockroughly half the current level in high-income countries. This

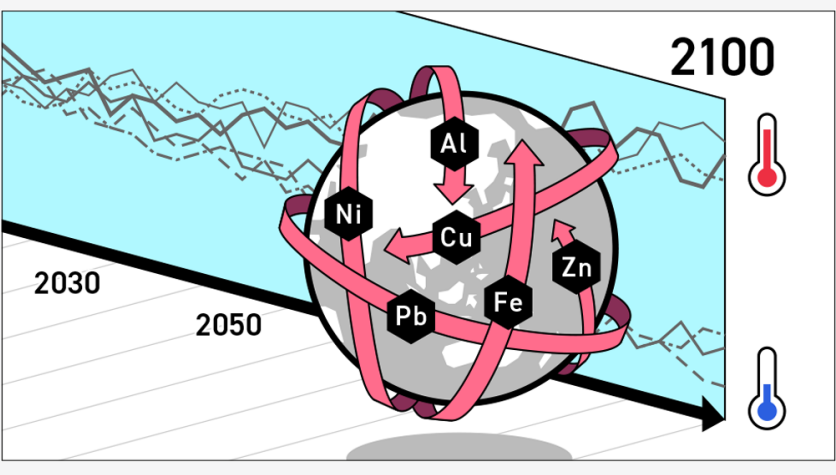
systemic change will require a peak in global metal production by 2030 and deep decoupling of economic growth from both metal flows and stocks. Importantly, the identified science-based targets are theoretically achievable through such measures as efficient design, more intensive use, and longer product lifetime, but immediate action is crucial before middle- and low-income countries complete full-scale urbanization.

\section{INTRODUCTION}

International agreement on both climate change mitigation ${ }^{1}$ and sustainable development ${ }^{2}$ poses a fundamental global challenge: how to satisfy the basic needs of an expanding global population without jeopardizing the $1.5-2{ }^{\circ} \mathrm{C}$ climate goals. Meeting this challenge calls for immediate changes in metal production and usage, which currently accounts for approximately $10 \%$ of global greenhouse-gas (GHG) emissions ${ }^{3}$ while underpinning vital services in a modern society in the form of products, factories, and infrastructures. ${ }^{4}$ Despite its importance, however, a clear vision of a future metal use system in harmony with long-term climate goals is lacking, impeding our ability to achieve an international consensus on global targets for metal flow, stock, and use intensity in the global economy based on a systematic understanding. ${ }^{5}$ One key to building this consensus is to explore future metal use scenarios that satisfy the metal service demands of future generations without compromising long-term climate goals and to develop a science-based target $(\mathrm{SBT})^{6-8}$ to accelerate concerted and innovative efforts by government and industry.

Technology-rich integrated assessment models are typically used to provide such scenarios by exploring possible technology mixes and their costs. ${ }^{9-11}$ However, this approach often fails to reflect the physical interconnection in the series of metal cycles ${ }^{12}$ that includes material production, manufacturing, in-use stock, and waste management, resulting in a weak foundation for explaining future demand and scrap availability. ${ }^{13}$ Furthermore, existing studies have focused strongly on innovative technology solutions such as carbon capture and storage (CCS) ${ }^{14}$ and hydrogen-based production, ${ }^{15}$ while metal cycle solutions, ${ }^{16}$ including circular economy $(\mathrm{CE})^{17}$ strategies, have tended to receive less attention. Although several studies ${ }^{4,18-20}$ have demonstrated important steps by systematically linking metal cycles to carbon emissions based on the principle of material flow analysis (MFA), such studies have failed to account for cumulative emissions-carbon budgets ${ }^{21}$ - and provide no explicit long-term or time-series targets for metal flows, stocks, and use intensity.

In this study, we develop global targets for metal flow, stock and use intensity out to 2100 harmonized with $2{ }^{\circ} \mathrm{C}$ climate goals using a dynamic MFA model coupled with an optimization routine and a global MFA system boundary incorporating 231 countries. Our approach explicitly deals with the physical interconnections of the entire metal cycle based on mass balance principles and carbon budgets, enabling the elucidation of the time series of metal flows, stocks, and efficiency required to meet the climate goal. Given the large uncertainties and environmental risks associated with innovative technology solutions, ${ }^{22}$ we aim to provide a benchmark indicating the extent to which

Received: April 20, 2020

Revised: August 27, 2020

Accepted: August 28, 2020

Published: September 11, 2020

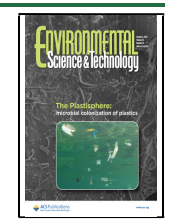


material efficiency needs to be improved if the innovative technologies fail to scale as planned. The metal cycle solutions considered in our analysis include product lifetime extension and improved end-of-life recycling based on the concept of a $\mathrm{CE}^{23}$ We also discuss strategies to meet basic human needs using less metal, including more intensive use of metal stocks, and efficient product design. ${ }^{24}$ As our aim is to cover metals that are widely used in modern society, we have included six major metals-iron, aluminum, copper, zinc, lead, and nickel-which account for more than $98 \%$ by mass of all metal production. ${ }^{25}$

\section{METHODS}

2.1. Historical Metal Flows and Stocks. Historical world flows and stocks of major metals from 1900 to 2010 are estimated by linking global MFA system boundaries for 231 countries $^{26,27}$ with a dynamic stock model ${ }^{28}$ that explicitly describes the multiyear physical interconnections of the entire metal cycle. ${ }^{29,30}$ In this modelling approach, the trade flows of metals contained in semimanufactured and finished products often cause mass imbalances because of data quality. This is resolved by adjusting the metal content and cut-off value for each trade commodity using a quadratic programming technique. $^{26}$ All metal flows in the 231 countries are then calculated based on the mass balance equations (eqs 1-13 in the Supporting Information). Stock dynamics aggregated according to the income level ${ }^{31}$ are estimated using the inflow-driven approach, ${ }^{32}$ assuming a specific lifetime for each product sector (Tables S2-S7).

2.2. Future Metal Flows and Stocks under the Carbon Budget. Future metal flows and stock dynamics aligning with the emission pathways of the $2{ }^{\circ} \mathrm{C}$ climate goal are explored by the optimization routine, which links to the dynamic stock model and emission intensities obtained from a life cycle assessment (LCA) database. ${ }^{33}$ The optimization routine determines the maximum production available under the annual carbon budget while aiming to minimize the divergence between supply and estimated baseline demand within the scenario period (2010 to 2100 ). In this case, the production includes both primary and secondary production; the latter covers two supply sources: new and old scrap. The new scrap is supplied from the yield generated at each processing stage; the old scrap is supplied from the outflow from the society as end-of-life products. Old scrap availability depends on the metabolism of the metal stock, and primary production is estimated as the remaining demand that cannot be satisfied by secondary production. The baseline demand is calculated based on future stock dynamics, which are determined under an assumption that global per capita in-use stocks follow growth patterns similar to those experienced by the current high-income countries. This trajectory does not take into account the emission constraints and is given as an exogenous variable to the optimization routine.

With regard to the emission intensities of each production route, we follow the method developed by Van der Voet and colleagues, ${ }^{34}$ who linked MFA with LCA to simulate the future environmental implications associated with metal demandsupply scenarios. The dataset distinguishes between primary and secondary production routes and is a time series from 2010 to 2100. We consider the potential of an ore grade decline (for copper, zinc, lead, and nickel), energy efficiency improvements in the primary production route (for iron and aluminum), and electricity system decarbonization that reduces indirect emissions (for all six metals) as in existing studies ${ }^{34}$ (see Figure
S3). Note that we assume here that future metal supply will not be limited by physical availability or any other environmental impacts such as biodiversity losses and water contaminations but is solely constrained by carbon emissions. Although our approach has some obvious limitations because of its simplification of several other factors (e.g., the rebound effect, market dynamics, and metal linkages), it nevertheless provides a useful stepping stone to explore future metal flows and stocks in line with Earth's carrying capacity. Detailed system boundaries, equations, data sources, and limitation descriptions can be found in the Supporting Information.

2.3. Scenario. 2.3.1. Metal Cycle Solution. We explore two scenarios for metal cycles in the $2{ }^{\circ} \mathrm{C}$ pathway: business as usual (BAU) and a CE. The BAU scenario assumes that all model parameters regarding the metal cycle are constant during the analysis period. The CE scenario, on the other hand, expects that the end-of-life recycling rate and product lifetime will rise to their theoretical maximum values from 2011 to 2100 by following a gradual saturation curve. Tables giving a detailed scenario parameter overview for the six metals are provided in Tables S2-S7 in the Supporting Information.

2.3.2. Innovative Technology Solution. We examine the implications of innovative technology developments such as CCS and hydrogen reduction, targeting iron and aluminum, for which a long-term roadmap ${ }^{35-38}$ has already been established. Metals other than iron and aluminum are excluded here as there are few roadmaps for innovative technologies, which makes it difficult to create scenarios. The detailed assumptions are as follows:

- Best available technology (BAT) for steel and aluminum making: The International Energy Agency estimated that the global emission reduction potential of BAT implementation for primary steel and aluminum production is 21 and $10 \%$, respectively. ${ }^{39}$ We assume that these are achieved from 2011 to 2050 by following the saturation curve.

- CCS and hydrogen reduction for steel making: the emission reduction target is set based on the long-term roadmap of the Japan Iron and Steel Federation for climate change mitigation: ${ }^{35}$ Accordingly, the CCS reduction is $20 \%$ and the hydrogen reduction is $10 \%$. As these technologies are expected to be implemented after 2030, we assume that the abovementioned reduction targets for primary production are achieved gradually from 2030 to 2060 for CCS and from 2050 to 2080 for hydrogen reduction.

- Superinnovative technologies for steel making (e.g., top gas recycling, bath smelting, direct reduction, and electrolysis): The European Steel Association (EUROFER) announced a more ambitious roadmap ${ }^{36}$ that aims for a $90 \%$ reduction by 2050 in the European Union by combining a series of technologies such as HIsarna (smelting reduction) and ULCORED (direct reduction), both connected to $\mathrm{CCS}$ or $\mathrm{CO}_{2}$-free hydrogen production. We assume that a $90 \%$ reduction for primary steel production is accomplished by 2100 on a global scale after obtaining the reduction effects of all the BAT, CCS, and hydrogen reduction solutions mentioned above.

- CCS and inert anodes for aluminum making: European Aluminum created a scenario for lower carbon direct emission reductions through CCS and inert anodes ${ }^{38}$ in the aluminum sector. The association projected that the 

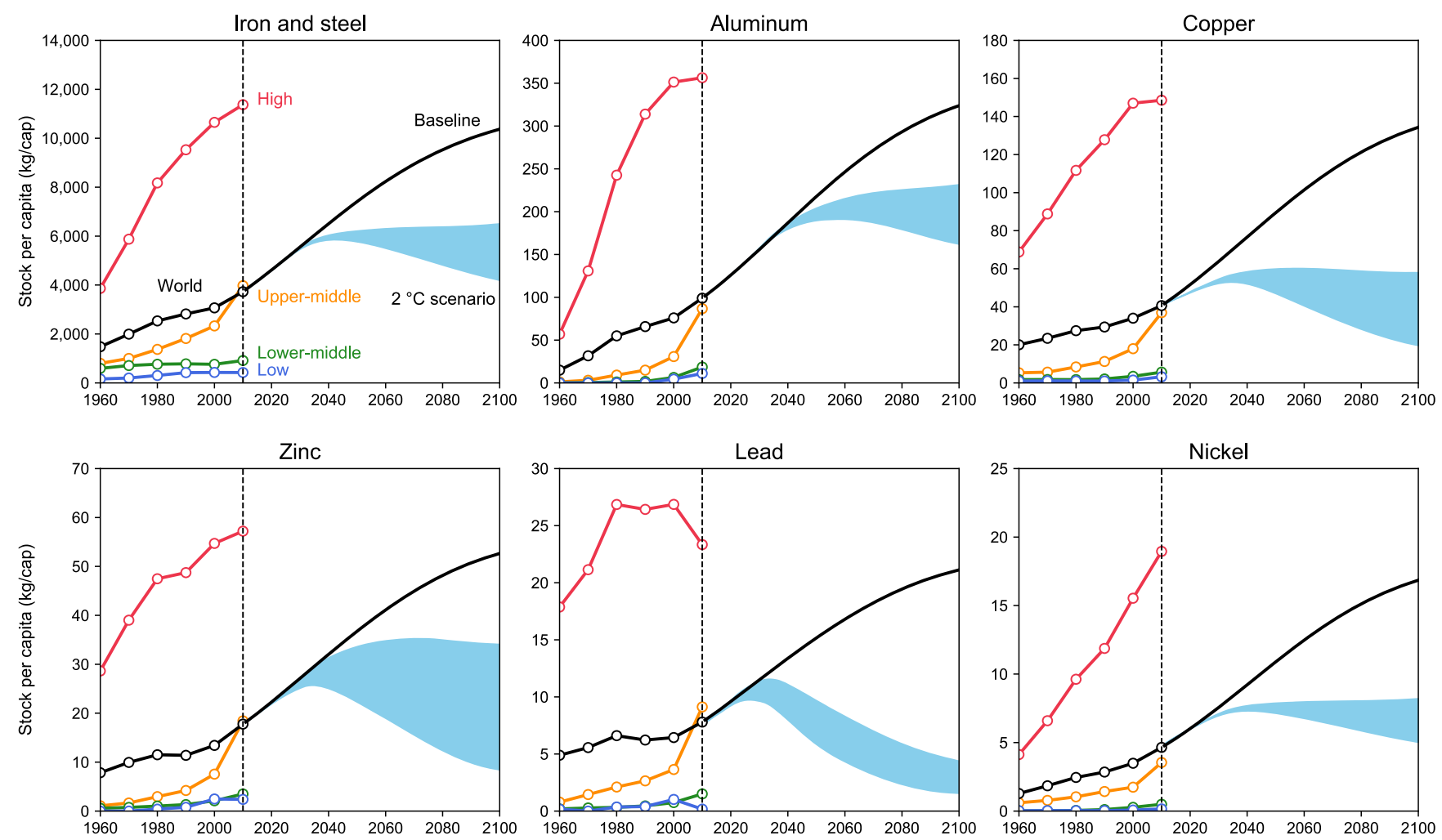

Figure 1. Per capita in-use stock for six major metals, 1960-2100. The ranges in the $2{ }^{\circ} \mathrm{C}$ scenario are due to differences in assumptions regarding the end-of-life recycling rate and product lifetime. The upper limit of the range (CE scenario) assumes that the end-of-life recycling rate and product lifetime increase to the theoretical maximum by 2100 according to the saturation curve. The lower limit of the range (BAU scenario) represents the assumption that all model parameters are constant throughout the scenario period.

implementation of these innovative technologies could reduce $23 \%$ of direct carbon emissions for primary aluminum production by 2050 in the European Union. We thus assume that a $23 \%$ reduction is achieved by 2100 on a global basis by following the saturation curve after 2030 .

Note that the potential for emission reductions by switching to renewable biofuels and charcoal instead of fossil fuels ${ }^{40}$ in thermal applications is not considered here because of the lack of a roadmap.

\section{RESULTS AND DISCUSSION}

3.1. In-Use Stock. Historically, in-use stocks of all major metals have been unevenly distributed across countries, based on the income level (Figure 1). Per capita stocks in high-income countries have shown a gradual growth or near-plateauing trend in recent years, reaching approximately $11,370 \mathrm{~kg} / \mathrm{cap}$ for iron, $360 \mathrm{~kg} / \mathrm{cap}$ for aluminum, $150 \mathrm{~kg} / \mathrm{cap}$ for copper, $57 \mathrm{~kg} / \mathrm{cap}$ for zinc, $23 \mathrm{~kg} /$ cap for lead, and $19 \mathrm{~kg} / \mathrm{cap}$ for nickel in 2010 . These levels are three to four times higher than the world average. On the other hand, the figures for upper-middle-income countries have remained at $20-40 \%$ of those in the high-income countries despite a sharp increase from around 2000. Most remarkably, lower-middle- and low-income countries have reached only 1$8 \%$ of the high-income country levels, suggesting a strong correlation between the major metal stock and economic level. These historical trends clearly illustrate a key challenge in the metal sector: how to achieve an absolute reduction in GHG emissions associated with major metal production while satisfying the increasing demand for metal services needed for purposes such as power generation, water sanitation, and basic infrastructure in low- and middle-income countries.

Our analysis shows that this fundamental challenge cannot be sufficiently addressed solely through aggressive scrap recycling and product lifetime extension. Figure 1 shows that the global average of per capita metal stocks cannot follow the historical evolution patterns of high-income countries because of carbon constraints in the $2{ }^{\circ} \mathrm{C}$ scenario. More specifically, per capita stocks of all major metals in the world average, except lead, need to saturate at levels 2-3 times lower than those that are currently the case in high-income countries: $6500 \mathrm{~kg} / \mathrm{cap}$ for iron, $230 \mathrm{~kg} /$ cap for aluminum, $58 \mathrm{~kg} /$ cap for copper, $34 \mathrm{~kg} /$ cap for zinc, 4 $\mathrm{kg} / \mathrm{cap}$ for lead, and $8 \mathrm{~kg} / \mathrm{cap}$ for nickel in 2100 . If the CE transition fails along with innovative production technologies, these values can be expected to be $40-75 \%$ lower (absolute stock dynamics can be seen in Figure S4). The variation in per capita stock dynamics by each metal is primarily due to the difference in average lifetime and potential for improved end-oflife recycling rate and emission intensity. For example, as aluminum has more room to reduce emission intensity by decarbonizing electricity systems and improving energy efficiency (Figure S3), its per capita stock dynamics under the $2{ }^{\circ} \mathrm{C}$ pathway are closer to the baseline than is the case for the other metals. Lead, in contrast, has a shorter average lifetime and has limited room for improving its end-of-life recycling rate and emission intensity, thus creating a downward trend rather than plateauing.

Overall, findings here indicate that metal cycle solutions limited to end-of-life recycling and product lifetime extension are unlikely to be sufficient for meeting the $2{ }^{\circ} \mathrm{C}$ climate goal in the metal sector. Satisfying the metal service demand of 10 

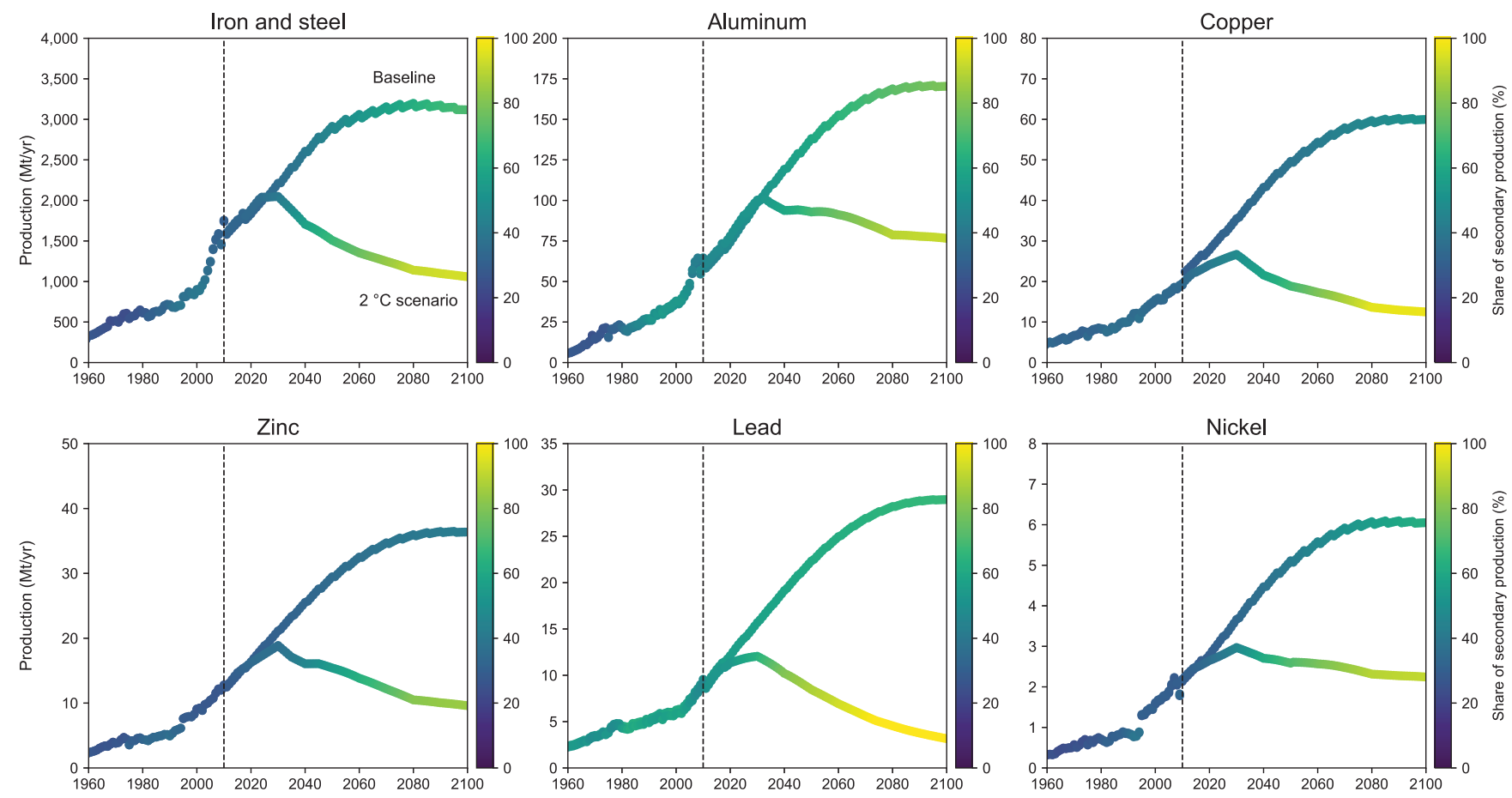

Figure 2. Production activities for six major metals, 1960-2100. The shade of the line color represents the ratio of secondary production to total production. The $2{ }^{\circ} \mathrm{C}$ scenario shows a case assuming increased end-of-life recycling rate and product lifetime (CE scenario).
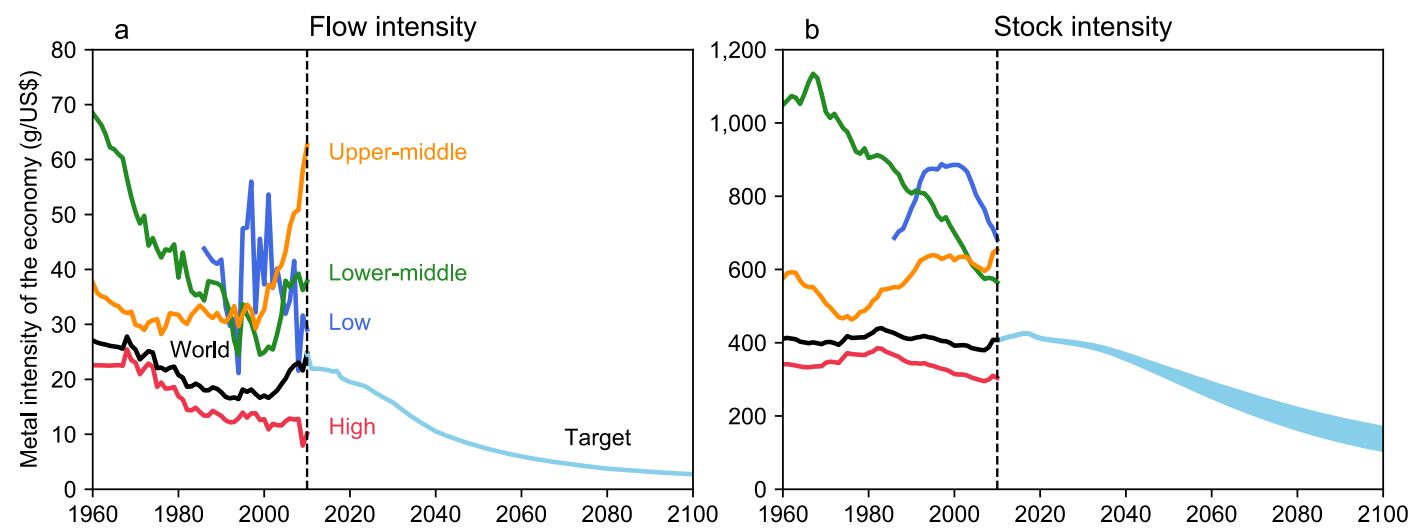

Figure 3. Metal use intensity in the global economy, 2010-2100: (a) metal flow intensity of the economy (metal inflows/GDP) and (b) metal stock intensity of the economy (metal stock/GDP). The ranges of the target are generated by the CE and BAU scenarios. Future GDP is based on SSP2, ${ }^{58}$ which represents a middle-of-the-road scenario.

billion people within the carbon budget will require a transformative system change to meet society's needs with less metal. One benchmark can be stabilizing the growth of global major metal in-use stock at around $7 \mathrm{t} / \mathrm{cap}$, which is approximately half the current level of high-income countries.

3.2. Primary and Secondary Production. For the world average to follow stock growth patterns similar to those of highincome countries, production activities will need to be increased by a factor of $2-3$ from 2010 to 2100 , depending on the metal (Figure 2). These estimates are consistent with those of a previous study ${ }^{41}$ (Figure S7). However, the carbon budget in line with the $2{ }^{\circ} \mathrm{C}$ goal significantly constrains production activities. Figure 2 clearly shows that the $2{ }^{\circ} \mathrm{C}$ scenario requires a production peak for all six major metals by around 2030. That is, an absolute decoupling of economic growth and metal production should be accomplished by no later than 2030 if we cannot rely on innovative technology solutions. The role of secondary production (production from scrap) is increasing over time, with approximately $54-87 \%$ of production coming from secondary production in 2050 and $84-100 \%$ in 2100 , with an increased end-of-life recycling rate. Primary production (production from ore), on the other hand, peaks around 20202030 and continues to decline thereafter. These results suggest that metal demand needs to be substantially curtailed if largescale implementation of the innovative technology solutions fails to scale. Realistically speaking, it is difficult to meet all of the demand with $100 \%$ secondary production because of quality issues $^{42}$ and thermodynamic reasons. ${ }^{43}$ Thus, production activities will be more restricted if we fail to develop an advanced recycling technology that enhances the quality of secondary production or product design harmonized with scrap utilization.

Potential per capita targets in this domain include stabilization at roughly $115.8 \mathrm{~kg} / \mathrm{cap}$ for iron, $8.4 \mathrm{~kg} / \mathrm{cap}$ for aluminum, 1.4 $\mathrm{kg} / \mathrm{cap}$ for copper, $1.1 \mathrm{~kg} / \mathrm{cap}$ for zinc, $0.3 \mathrm{~kg} / \mathrm{cap}$ for lead, and $0.2 \mathrm{~kg} / \mathrm{cap}$ for nickel until 2100 (Figure S6). These values are 2- 


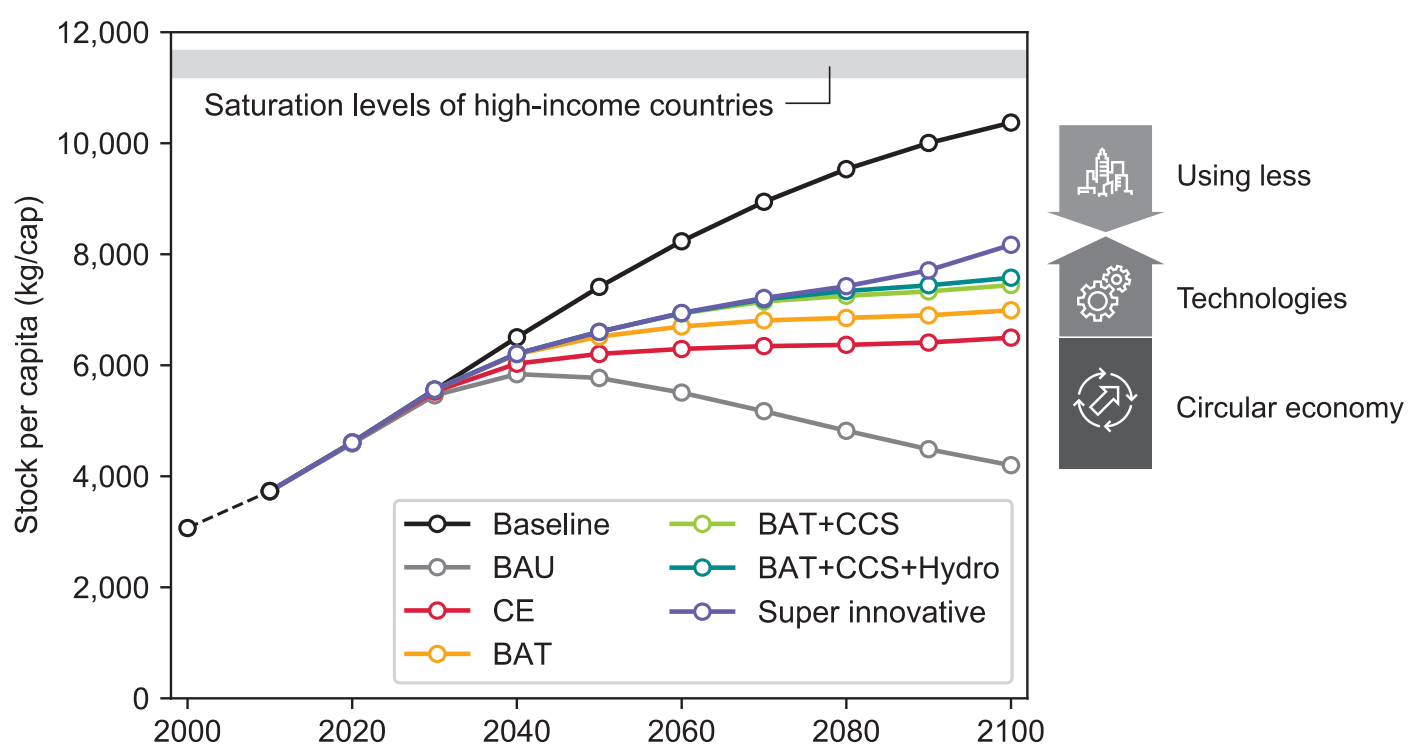

Figure 4. Per capita in-use stock of iron and steel with the various innovative technology solutions, 2000-2100. The horizontal grey area indicates the current saturation levels in high-income countries. The baseline represents the stock growth pattern without carbon constraints. CE assumes increased end-of-life recycling rate and product lifetime, while BAU assumes a constant value of these parameters in the $2{ }^{\circ} \mathrm{C}$ scenario. Abbreviations for innovative production technologies are as follows: best available technology (BAT), carbon capture and storage (CCS), and hydrogen reduction (Hydro). Superinnovative technologies include top gas recycling, bath smelting, direct reduction, and electrolysis.

9 times lower than those in current high-income countries, underscoring the urgent need to break the coupling of economic growth and metal demand. ${ }^{44}$

3.3. Metal Use Intensity. To what extent should we promote decoupling in the coming decades? This question is addressed by linking the metal flows and stock dynamics identified above to the shared socioeconomic pathways (SSPs). ${ }^{45}$ Here, we define the metal use intensity of the economy (g-metals/GDP) — that is, the physical metal flow or in-use stock per unit of economic activity-as an indicator of decoupling. ${ }^{46}$

Figure 3 illustrates the urgent need for a significant decrease in the metal use intensity of the global economy over the 21 st century and the difficulty of achieving this decrease. The historical metal flow intensity of the global economy shows gradual improvements before 2000 but deteriorates after this period because of a drastic increase in upper-middle-income countries, mainly China. Intensity targets in line with the $2{ }^{\circ} \mathrm{C}$ goal call for an immediate change in this situation. Figure 3 shows that the metal flow intensity needs to be reduced by $36 \%$ by $2030,70 \%$ by 2050 , and $90 \%$ by 2100 relative to 2010 , meaning a strong decoupling of global metal production from economic activities.

We also confirm the importance of improving metal stock intensity in parallel with flow intensity. Stock intensity provides better insights into the nexus of service provision and metal use, as metal services are delivered in the form of stocks such as buildings and vehicles. ${ }^{4}$ Historically, the metal stock intensity of the global economy has not improved significantly, remaining at roughly $400 \mathrm{~g} / \mathrm{US} \$$. This observation is consistent with trends observed in previous studies ${ }^{47}$ involving comprehensive materials such as cement and biomass. This tight coupling, however, needs to be severely broken in the 21 st century. The identified targets for metal stock intensity are to reduce it by $3-$ $4 \%$ by $2030,20-25 \%$ by 2050 , and $60-75 \%$ by 2100 relative to 2010 levels, depending on whether we assume an increased endof-life recycling rate and an extended product lifetime.
These targets intrinsically depend on the assumed socioeconomic future and vary widely among SSP scenarios (Figure S8). However, given the significant uncertainties, our results consistently support the hypothesis that the $2{ }^{\circ} \mathrm{C}$ pathway requires continuous and substantial decoupling during the 21 st century. Importantly, achieving the specified targets will allow us to align the GHG emissions in the metal sector with the $2{ }^{\circ} \mathrm{C}$ pathway without relying on technologies, whose applicability on a global scale is still unclear and may involve serious socioenvironmental trade-offs. ${ }^{22}$

3.4. Potential of Innovative Technology Solutions. Despite the large uncertainty, innovative technology solutions such as CCS and hydrogen reduction are currently considered central options for climate change mitigation. ${ }^{14,48}$ Thus, it is worth investigating the potential impacts of these technologies on the future metal use scenario, specifically targeting iron and aluminum, for which a long-term roadmap ${ }^{35-38}$ is already established. Figure 4 shows that the various innovative technologies are not likely to be sufficient to maintain the available amount of iron stock at the current level of highincome countries within the carbon budget corresponding to the $2{ }^{\circ} \mathrm{C}$ goal (see Figure S9 for aluminum). The combination of $\mathrm{BAT}, \mathrm{CCS}$, and hydrogen reduction can contribute to raising the iron stock to $7600 \mathrm{~kg} / \mathrm{cap}$ in 2100 . Implementing superinnovative technologies, which are currently only in the laboratory stage, such as $\mathrm{CO}_{2}$-free hydrogen and electrolysis, has further promise of increasing the iron stock to $8200 \mathrm{~kg} / \mathrm{cap}$. Still, none of these scenarios match the baseline scenario that follows a similar stock growth pattern as that of the high-income countries. Similarly, the implementation of BAT, CCS, and inert anodes in aluminum making has a limited effect on the stock available under carbon constraints (Figure S9). This indicates that climate policy making for the metal sector that focuses only on innovative technology solutions may be highly problematic. The remaining gap needs to be filled by transitioning to a society in which the same services are delivered with less metal. 
3.5. Identified Target is Theoretically Achievable. Lack of international consensus on the sustainable level of resource use is currently preventing agreement on global resource use targets. ${ }^{49}$ The present study bridges this important knowledge gap. Our analysis, which is based on the explicit link between MFA and the carbon budget, provides a benchmark indicating the extent to which metal use intensity in the global economy needs to be curtailed by decoupling both metal flows and stocks from economic activities.

Specifically, we find that global metal stock should be saturated at around $7 \mathrm{t} / \mathrm{cap}(6500 \mathrm{~kg} / \mathrm{cap}$ for iron, $230 \mathrm{~kg} / \mathrm{cap}$ for aluminum, $58 \mathrm{~kg} /$ cap for copper, $34 \mathrm{~kg} /$ cap for zinc, $4 \mathrm{~kg} /$ cap for lead, and $8 \mathrm{~kg} / \mathrm{cap}$ for nickel), which is approximately half the current level of high-income countries. Can this level of metal use meet the basic needs of future generations? What strategic options exist? Our simplified estimation, based on a literature review, ${ }^{4,18,50}$ suggests that the $7 \mathrm{t} /$ cap metal stock could deliver sufficient services for the expanding global population by implementing cross-cutting material efficiency strategies over the entire metal/product life-cycle. This includes more intensive use of metal stocks and more efficient design (Figure S10), facilitated through well-coordinated policy packages such as virgin material taxes, green public procurement, and a materialefficient design certification scheme. ${ }^{51}$ Obviously, the difficulty of implementing these strategies will differ greatly depending on the metal, and future market trends will affect the ease with which demand reduction can be achieved (e.g., the demand for lead may suffer given its dominant use in lead-acid car batteries, $^{52}$ while the demand for copper and nickel may increase through lithium-battery technology in electric vehicles or offshore wind $\left.{ }^{53,54}\right)$. In any case, urgent action is critical, as the time required for designing and implementing effective policies is likely to be extensive. If such urgency is absent, the metal sector may well contribute to the overshooting of annual emission targets, leading to more stringent reduction requirements in the second half of the 21 st century. ${ }^{55}$ In this context, it is important to link the metal use targets identified in this study with urban development planning in middle- and low-income countries in the 21st century, as major metals are deeply connected to basic urban components such as buildings and infrastructures. ${ }^{56}$ With the per capita stocks in these countries still well below the target, we now have an important opportunity to meet the needs of future generations with much less metal by a careful urban design that can stimulate a deep decoupling.

3.6. Climate Policy Should Cover Material Efficiency. Despite the key role of decoupling metal use from economic growth in climate change mitigation, much about material efficiency strategies ${ }^{57}$ remains unknown or ill defined, including their full potential, barriers to their implementation, and the trade-offs involved. Scientific knowledge regarding policy instruments and their costs also remains unclear. Notably, the latest International Resource Panel report ${ }^{51}$ points out that commitments to material efficiency have been scarcely incorporated into the nationally determined contributions of the Paris Agreement. An important step would be to include material efficiency strategies in the list of climate change mitigation options, taking into account specific policy alternatives and their costs. Broadening the horizons of policy makers, business leaders, and consumers is an essential challenge if they are to see and understand the full range of opportunities across the entire life cycle and value chain. If science-based policy instruments work properly, the metal sector can potentially provide sufficient emission abatement while meeting the basic needs of an expanding global population. The fundamental question is whether we can act fast enough before today's middle- and low-income countries complete full-scale urbanization.

\section{ASSOCIATED CONTENT}

\section{Supporting Information}

The Supporting Information is available free of charge at https://pubs.acs.org/doi/10.1021/acs.est.0c02471.

Modeling framework; data and parameter overview; material efficiency strategies; additional results; limitations; and other data (PDF)

\section{AUTHOR INFORMATION}

\section{Corresponding Author}

Takuma Watari - Center for Material Cycles and Waste Management Research, National Institute for Environmental Studies, Tsukuba, Ibaraki 305-8506, Japan; Graduate School of Frontier Sciences, The University of Tokyo, Kashiwa, Chiba 2778563, Japan; 이이이.org/0000-0002-6072-3679;

Phone: +81-90-1683-1475; Email: watari.takuma@nies.go.jp

\section{Authors}

Keisuke Nansai - Center for Material Cycles and Waste Management Research, National Institute for Environmental Studies, Tsukuba, Ibaraki 305-8506, Japan; Centre for Integrated Sustainability Analysis, School of Physics, Faculty of Science, The University of Sydney, Camperdown, New South Wales 2006, Australia; 10 orcid.org/0000-0002-2449-1874

Damien Giurco - Institute for Sustainable Futures, University of Technology Sydney, Ultimo, New South Wales 2007, Australia

Kenichi Nakajima - Center for Material Cycles and Waste Management Research, National Institute for Environmental Studies, Tsukuba, Ibaraki 305-8506, Japan; Graduate School of Frontier Sciences, The University of Tokyo, Kashiwa, Chiba 2778563, Japan; 이이이.org/0000-0002-7241-7695

Benjamin McLellan - Graduate School of Energy Science, Kyoto University, Kyoto 606-8501, Japan; 이이.org/0000-00024802-3864

Christoph Helbig - Resource Lab, University of Augsburg, Augsburg 86159, Germany; 이이이.org/0000-0001-6709373X

Complete contact information is available at: https://pubs.acs.org/10.1021/acs.est.0c02471

\section{Author Contributions}

T.W. coordinated the research, performed the analysis, created the figures, and led the writing of the paper. Keisuke Nansai, Kenichi Nakajima, and C.H. contributed to the model and scenario design. Keisuke Nansai, B.M., and D.G. aided in interpreting the results and worked on the manuscript. All authors provided critical feedback and helped shape the research, analysis, and manuscript.

\section{Notes}

The authors declare no competing financial interest.

\section{ACKNOWLEDGMENTS}

This research was supported in part by Grants-in-Aid for Research (nos. 19K24391, 18KT0056 and 18KT0010) from the Japanese Ministry of Education, Culture, Sports, Science and Technology and by the Environment Research and Technology 
Development Fund (JPMEERF20182001 and 20S20620) of the Environmental Restoration and Conservation Agency of Japan. We thank Dr. Yasuaki Hijioka, Dr. Minoru Fujii, and Wataru Takayanagi for providing helpful comments.

\section{REFERENCES}

(1) UNFCCC. Adoption of the Paris Agreement; Paris, France, 2015.

(2) UN General Assembly. Transforming Our World: The 2030

Agenda for Sustainable Development: New York, 2015.

(3) IRP. Global Resources Outlook 2019; Nairobi, Kenya, 2019.

(4) Pauliuk, S.; Müller, D. B. The Role of In-Use Stocks in the Social Metabolism and in Climate Change Mitigation. Global Environ. Change 2014, 24, 132-142.

(5) Ali, S. H.; Giurco, D.; Arndt, N.; Nickless, E.; Brown, G.; Demetriades, A.; Durrheim, R.; Enriquez, M. A.; Kinnaird, J.; Littleboy, A.; Meinert, L. D.; Oberhänsli, R.; Salem, J.; Schodde, R.; Schneider, G.; Vidal, O.; Yakovleva, N. Mineral Supply for Sustainable Development Requires Resource Governance. Nature 2017, 543, 367-372.

(6) Science Based Targets. What is a science based targets?. https:// sciencebasedtargets.org/ (accessed Dec 11, 2019).

(7) Bringezu, S. Possible Target Corridor for Sustainable Use of Global Material Resources. Resources 2015, 4, 25-54.

(8) Bringezu, S. Toward Science-Based and Knowledge-Based Targets for Global Sustainable Resource Use. Resources 2019, 8 (). DOI: $10.3390 /$ resources8030140.

(9) IPCC. Climate Change 2014: Mitigation of Climate Change; United Kingdom and New York, NY, USA, 2014.

(10) IEA. Energy Technology Perspectives 2017: Catalysing Energy Technology Transformations Together Secure Sustainable; Paris, France, 2017.

(11) Fujimori, S.; Oshiro, K.; Shiraki, H.; Hasegawa, T. Energy Transformation Cost for the Japanese Mid-Century Strategy. Nat. Commun. 2019, 10, 4737.

(12) Pauliuk, S.; Arvesen, A.; Stadler, K.; Hertwich, E. G. Industrial Ecology in Integrated Assessment Models. Nat. Clim. Change 2017, 7, 13-20.

(13) Müller, D. B.; Wang, T.; Duval, B. Patterns of Iron Use in Societal Evolution. Environ. Sci. Technol. 2011, 45, 182-188.

(14) Van Ruijven, B. J.; Van Vuuren, D. P.; Boskaljon, W.; Neelis, M. L.; Saygin, D.; Patel, M. K. Long-Term Model-Based Projections of Energy Use and $\mathrm{CO} 2$ Emissions from the Global Steel and Cement Industries. Resour., Conserv. Recycl. 2016, 112, 15-36.

(15) Morfeldt, J.; Nijs, W.; Silveira, S. The Impact of Climate Targets on Future Steel Production - An Analysis Based on a Global Energy System Model. J. Cleaner Prod. 2015, 103, 469-482.

(16) Creutzig, F.; Roy, J.; Lamb, W. F.; Azevedo, I. M. L.; Bruine De Bruin, W.; Dalkmann, H.; Edelenbosch, O. Y.; Geels, F. W.; Grubler, A.; Hepburn, C.; Hertwich, E. G.; Khosla, R.; Mattauch, L.; Minx, J. C.; Ramakrishnan, A.; Rao, N. D.; Steinberger, J. K.; Tavoni, M.; ÜrgeVorsatz, D.; Weber, E. U. Towards Demand-Side Solutions for Mitigating Climate Change. Nat. Clim. Change 2018, 8, 260-271.

(17) Stahel, W. R. Circular Economy. Nature 2016, 531, 435-438.

(18) Milford, R. L.; Pauliuk, S.; Allwood, J. M.; Müller, D. B. The Roles of Energy and Material Efficiency in Meeting Steel Industry CO2 Targets. Environ. Sci. Technol. 2013, 47, 3455-3462.

(19) Liu, G.; Bangs, C. E.; Müller, D. B. Stock Dynamics and Emission Pathways of the Global Aluminum Cycle. Nat. Clim. Change 2013, 3, 338.

(20) Jens, G.; Lehmann, H.; Lorenz, U.; Purr, K. A Resource Efficient Pathway towards a Greenhouse Gas Neutral Germany, 2019.

(21) Rogelj, J.; Forster, P. M.; Kriegler, E.; Smith, C. J.; Séférian, R. Estimating and Tracking the Remaining Carbon Budget for Stringent Climate Targets. Nature 2019, 571, 335-342.

(22) Von Stechow, C.; Minx, J. C.; Riahi, K.; Jewell, J.; McCollum, D. L.; Callaghan, M. W.; Bertram, C.; Luderer, G.; Baiocchi, G. $2^{\circ} \mathrm{C}$ and SDGs: United They Stand, Divided They Fall? Environ. Res. Lett. 2016, 11 (). DOI: $10.1088 / 1748-9326 / 11 / 3 / 034022$.
(23) Kirchherr, J.; Reike, D.; Hekkert, M. Conceptualizing the Circular Economy: An Analysis of 114 Definitions. Resour., Conserv. Recycl. 2017, 127, 221-232.

(24) Allwood, J. M.; Ashby, M. F.; Gutowski, T. G.; Worrell, E. Material Efficiency: A White Paper. Resour., Conserv. Recycl. 2011, 55, $362-381$.

(25) U.S. Geological Survey. Commodity Statistics and Information. https://minerals.usgs.gov/minerals/pubs/mcs/ (accessed 2020).

(26) Nansai, K.; Nakajima, K.; Kagawa, S.; Kondo, Y.; Suh, S.; Shigetomi, Y.; Oshita, Y. Global Flows of Critical Metals Necessary for Low-Carbon Technologies: The Case of Neodymium, Cobalt, and Platinum. Environ. Sci. Technol. 2014, 48, 1391-1400.

(27) Nakajima, K.; Daigo, I.; Nansai, K.; Matsubae, K.; Takayanagi, W.; Tomita, M.; Matsuno, Y. Global Distribution of Material Consumption: Nickel, Copper, and Iron. Resour., Conserv. Recycl. 2018, 133, 369-374.

(28) Müller, E.; Hilty, L. M.; Widmer, R.; Schluep, M.; Faulstich, M. Modeling Metal Stocks and Flows: A Review of Dynamic Material Flow Analysis Methods. Environ. Sci. Technol. 2014, 48, 2102-2113.

(29) Pauliuk, S.; Heeren, N. ODYM - An Open Software Framework for Studying Dynamic Material Systems Principles , Implementation , and Data Structures. J. Ind. Ecol. 2019, 24, 446.

(30) Helbig, C.; Thorenz, A.; Tuma, A. Quantitative Assessment of Dissipative Losses of 18 Metals. Resour., Conserv. Recycl. 2020, 153, 104537.

(31) The World Bank. DataBank https://databank.worldbank.org/ databases (accessed Dec 16, 2019).

(32) Wiedenhofer, D.; Fishman, T.; Lauk, C.; Haas, W.; Krausmann, F. Integrating Material Stock Dynamics Into Economy-Wide Material Flow Accounting: Concepts, Modelling, and Global Application for 1900-2050. Ecol. Econ. 2019, 156, 121-133.

(33) Frischknecht, R.; Jungbluth, N.; Althaus, H.-J.; Doka, G.; et al. The Ecoinvent Database: Overview and Methodological Framework. Int. J. Life Cycle Assess. 2005, 10, 3-9.

(34) Van der Voet, E.; Van Oers, L.; Verboon, M.; Kuipers, K. Environmental Implications of Future Demand Scenarios for Metals: Methodology and Application to the Case of Seven Major Metals. J. Ind. Ecol. 2019, 23, 141-155.

(35) The Japan Iron and Steel Federation. JISF Long-Term Vision for Climate Change Mitigation; Tokyo, Japan, 2019.

(36) EUROFER. A Steel Roadmap for A Low Carbon Europe 2050; Brussels, Belgium, 2013.

(37) JRC. Prospective Scenarios on Energy Efficiency and CO2Emissions in the EU Iron \& Steel Industry; 2012.

(38) European Aluminium. Vision 2050 European Aluminum's Contribution to the EU's Mid-Century Low-Carbon Roadmap; Brussels, Belgium, 2019.

(39) IEA. Energy Technology Perspectives 2014 -Harnessing Electricity's Potential; Paris, France, 2014.

(40) McLellan, B. C.; Corder, G. D.; Giurco, D. P.; Ishihara, K. N. Renewable Energy in the Minerals Industry: A Review of Global Potential. J. Cleaner Prod. 2012, 32, 32-44.

(41) Elshkaki, A.; Graedel, T. E.; Ciacci, L.; Reck, B. K. Resource Demand Scenarios for the Major Metals. Environ. Sci. Technol. 2018, 52, 2491-2497.

(42) Nakamura, S.; Kondo, Y.; Matsubae, K.; Nakajima, K.; Tasaki, T.; Nagasaka, T. Quality- and Dilution Losses in the Recycling of Ferrous Materials from End-of-Life Passenger Cars: Input-Output Analysis under Explicit Consideration of Scrap Quality. Environ. Sci. Technol. 2012, 46, 9266-9273.

(43) Reuter, M. A.; van Schaik, A.; Gutzmer, J.; Bartie, N.; AbadíasLlamas, A. Challenges of the Circular Economy: A Material, Metallurgical, and Product Design Perspective. Annu. Rev. Mater. Res. 2019, 49, 253-274.

(44) Zheng, X.; Wang, R.; Wood, R.; Wang, C.; Hertwich, E. G. High Sensitivity of Metal Footprint to National GDP in Part Explained by Capital Formation. Nat. Geosci. 2018, 11, 269-273.

(45) Riahi, K.; van Vuuren, D. P.; Kriegler, E.; Edmonds, J.; O’Neill, B. C.; Fujimori, S.; Bauer, N.; Calvin, K.; Dellink, R.; Fricko, O.; Lutz, W.; 
Popp, A.; Cuaresma, J. C.; Kc, S.; Leimbach, M.; Jiang, L.; Kram, T.; Rao, S.; Emmerling, J.; Ebi, K.; Hasegawa, T.; Havlik, P.; Humpenöder, F.; Da Silva, L. A.; Smith, S.; Stehfest, E.; Bosetti, V.; Eom, J.; Gernaat, D.; Masui, T.; Rogelj, J.; Strefler, J.; Drouet, L.; Krey, V.; Luderer, G.; Harmsen, M.; Takahashi, K.; Baumstark, L.; Doelman, J. C.; Kainuma, M.; Klimont, Z.; Marangoni, G.; Lotze-Campen, H.; Obersteiner, M.; Tabeau, A.; Tavoni, M. The Shared Socioeconomic Pathways and Their Energy, Land Use, and Greenhouse Gas Emissions Implications: An Overview. Global Environ. Change 2017, 42, 153-168.

(46) Schandl, H.; Fischer-Kowalski, M.; West, J.; Giljum, S.; Dittrich, M.; Eisenmenger, N.; Geschke, A.; Lieber, M.; Wieland, H.; Schaffartzik, A.; Krausmann, F.; Gierlinger, S.; Hosking, K.; Lenzen, M.; Tanikawa, H.; Miatto, A.; Fishman, T. Global Material Flows and Resource Productivity Forty Years of Evidence. J. Ind. Ecol. 2018, 22, 827-838.

(47) Krausmann, F.; Wiedenhofer, D.; Lauk, C.; Haas, W.; Tanikawa, H.; Fishman, T.; Miatto, A.; Schandl, H.; Haberl, H. Global Socioeconomic Material Stocks Rise 23-Fold over the 20th Century and Require Half of Annual Resource Use. Proc. Natl. Acad. Sci. U.S.A. 2017, 114, 1880-1885.

(48) Pardo, N.; Moya, J. A. Prospective Scenarios on Energy Efficiency and $\mathrm{CO} 2$ Emissions in the European Iron \& Steel Industry. Energy 2013, 54, 113-128.

(49) World Economic Forum. The Next Frontier: Natural Resource Targets Shaping a Competitive Circular Economy within Planetary Boundaries; Cologny, Switzerland, 2019.

(50) Allwood, J. M.; Cullen, J. M.; Milford, R. L. Options for Achieving a $50 \%$ Cut in Industrial Carbon Emissions by 2050. Environ. Sci. Technol. 2010, 44, 1888-1894.

(51) IRP. Resource Efficiency and Climate Change: Material Efficiency Strategies for a Low-Carbon Future; Nairobi, Kenya, 2020.

(52) Tokimatsu, K.; Murakami, S.; Adachi, T.; Ii, R.; Yasuoka, R.; Nishio, M. Long-Term Demand and Supply of Non-Ferrous Mineral Resources by a Mineral Balance Model. Miner. Econ. 2017, 30, 193206.

(53) Watari, T.; McLellan, B. C.; Giurco, D.; Dominish, E.; Yamasue, E.; Nansai, K. Total Material Requirement for the Global Energy Transition to 2050: A Focus on Transport and Electricity. Resour., Conserv. Recycl. 2019, 148, 91-103.

(54) Watari, T.; Nansai, K.; Nakajima, K. Review of Critical Metal Dynamics to 2050 for 48 Elements. Resour., Conserv. Recycl. 2020, 155, 104669.

(55) Rogelj, J.; Huppmann, D.; Krey, V.; Riahi, K.; Clarke, L.; Gidden, M.; Nicholls, Z.; Meinshausen, M. A New Scenario Logic for the Paris Agreement Long-Term Temperature Goal. Nature 2019, 573, 357363.

(56) Müller, D. B.; Liu, G.; Løvik, A. N.; Modaresi, R.; Pauliuk, S.; Steinhoff, F. S.; Brattebø, H. Carbon Emissions of Infrastructure Development. Environ. Sci. Technol. 2013, 47, 11739-11746.

(57) Hertwich, E. G.; Ali, S.; Ciacci, L.; Fishman, T.; Heeren, N.; Masanet, E.; Asghari, F. N.; Olivetti, E.; Pauliuk, S.; Tu, Q.; Wolfram, P. Material Efficiency Strategies to Reducing Greenhouse Gas Emissions Associated with Buildings, Vehicles, and Electronics-a Review. Environ. Res. Lett. 2019, 14, 043004.

(58) Fricko, O.; Havlik, P.; Rogelj, J.; Klimont, Z.; Gusti, M.; Johnson, N.; Kolp, P.; Strubegger, M.; Valin, H.; Amann, M.; Ermolieva, T.; Forsell, N.; Herrero, M.; Heyes, C.; Kindermann, G.; Krey, V.; McCollum, D. L.; Obersteiner, M.; Pachauri, S.; Rao, S.; Schmid, E.; Schoepp, W.; Riahi, K. The Marker Quantification of the Shared Socioeconomic Pathway 2: A Middle-of-the-Road Scenario for the 21st Century. Global Environ. Change 2017, 42, 251-267. 